\title{
Editorial
}

\section{Hydrological Processes in Changing Climate, Land Use, and Cover Change}

\author{
Yongqiang Zhang, ${ }^{1}$ Fubao Sun, ${ }^{2}$ Ming Pan, ${ }^{3}$ Tom Van Niel, ${ }^{4}$ and Martin Wegehenkel ${ }^{5}$ \\ ${ }^{1}$ CSIRO Land and Water Flagship, P.O. Box 1666, Canberra, ACT 2601, Australia \\ ${ }^{2}$ The Institute of Geographic Sciences and Natural Resources Research (IGSNRR), Chinese Academy of Sciences, Beijing 100101, China \\ ${ }^{3}$ Department of Civil and Environmental Engineering, Princeton University, NJ 08544, USA \\ ${ }^{4}$ CSIRO Land and Water, Private Bag No. 5, Wembley, WA 6913, Australia \\ ${ }^{5}$ Institute of Landscape Systems Analysis, Leibniz Centre for Agricultural Landscape Research, Eberswalder Straße 84, \\ 15374 Müncheberg, Germany
}

Correspondence should be addressed to Yongqiang Zhang; yongqiang.zhang@csiro.au

Received 20 August 2015; Accepted 27 August 2015

Copyright @ 2016 Yongqiang Zhang et al. This is an open access article distributed under the Creative Commons Attribution License, which permits unrestricted use, distribution, and reproduction in any medium, provided the original work is properly cited.

Global environmental change, such as climate change, land use, and land cover change, is noticeably influencing hydrological processes from catchment to regional and to global scales, resulting in hydrologic nonstationarity. Therefore, it is urgent to improve our skills or methods to better understand mechanism of hydrological processes under global environmental change. This needs multidisciplinary studies that involve hydrology, meteorology, remote sensing, ecology, agriculture, and so forth.

We were invited by this journal to propose this special issue in June 2014. Researchers across globe were invited to contribute their original research articles to this special issue.

This special issue received high attention from hydrology, meteorology, remote sensing, agriculture, and ecology communities. The accepted papers cover wide ranges of topics, including (1) introducing physical/statistical methodologies and models to simulate hydrological processes in various spatial scales; (2) using various techniques/methods/models to separate climate change, land use, and cover change impact on hydrological processes; (3) detecting trends and variation of hydrological variables, such as runoff, actual evapotranspiration, and soil moisture.

There are papers studying predicting runoff, estimating runoff, and other water balance components' response to climate change and land cover changes. N. Ohana-Levi et al. (2015) modelled the effects of land cover change on rainfallrunoff relationships in a semiarid, eastern Mediterranean watershed. Z. Lu et al. (2015) introduced a case study in the Loess Plateau investigating hydrologic responses to land use change. S. Zeng et al. (2015) studied effects of climate change and human activities on surface runoff in the Luan River Basin. G. Qin et al. (2015) simulated hydrologic variations and stochastic modeling of runoff in Zoige wetland in the Eastern Tibetan Plateau. H. Li et al. (2015) introduced a review paper summarizing state-of-the-art studies for predicting surface runoff from catchment to large region. W. Yang et al. (2015) explored the process of extreme floods by using multivariate analysis to characterize flood and precipitation event data in combination with historical data and simulated from global climate models for the water source area for the middle route of south-to-north water diversion project, China. G. Fang et al. (2015) investigated future climate change influencing runoff availability in Kaidu River Basin in the Tianshan Mountains. M. Szwed (2015) estimated changes in water balance components including precipitation, evaporation, and runoff between the historic period (1961-1990) and future period (2071-2100) in Poland.

There are papers investigating improving precipitation data accuracy, estimating drought and precipitation indices. H. Lee and K. Kang (2015) conducted interpolation of missing precipitation data using kernel estimations for hydrologic modeling. V. M. Rodríguez-Moreno et al. (2015) used serial analysis of ten precipitation-based indices by land use in the semiarid physiographic province of Mesa Central, Mexico. 
X. Zhou et al. (2015) compared two approaches for estimating precipitation elasticity of streamflow in China's main river basins. Y. Zhang et al. (2015) estimated changes in precipitation and drought in Aksu River Basin, Northwest China.

There are papers addressing river and catchment environmental issues. X. Liu et al. (2015) conducted "Research on Nonpoint Source Pollution Assessment Method in Data Sparse Regions: A Case Study of Xichong River Basin, China.” J. Song et al. (2015) evaluated river health for the Weihe River in Shaanxi Province, China.

The rest of the papers focus on various hydrological and ecohydrological topics from small catchments to large regions. S. B. Foster and D. M. Allen (2015) used a coupled numerical model to investigate groundwater and surface water interactions in a mountain-to-coast watershed in British Columbia, Canada. D. Yin et al. (2015) identified vegetation dynamics and sensitivities in response to water resources management in the Heihe River Basin in China. C. Toledo et al. (2015) compared stationary and dynamic conceptual models for estimating hydrological processes in a mountainous and data-sparse catchment in the southcentral Chilean Andes. H. Gao et al. (2015) used remote sensing observations to detect interannual variation of the surface temperature of tropical forests over Amazon and Congo rainforests. A. A. Assani et al. (2015) compared spatiotemporal variability of temperature and precipitation with that of the magnitude and timing of maximum daily spring flow in L'Assomption River (agricultural) and Matawin River (forested) watersheds in Quebec, Canada. Q. Guo et al. (2015) proposed an approach for web-based data integration and interoperability for a massive spatial-temporal dataset of the Heihe River Basin framework.

\section{Acknowledgments}

We thank this journal for providing us with the opportunity to publish this special issue. We also thank all reviewers for their critical comments and constructive suggestions for selecting high-quality studies and improving quality of the papers published in this special issue.

Yongqiang Zhang Fubao Sun Ming Pan

Tom Van Niel

Martin Wegehenkel 

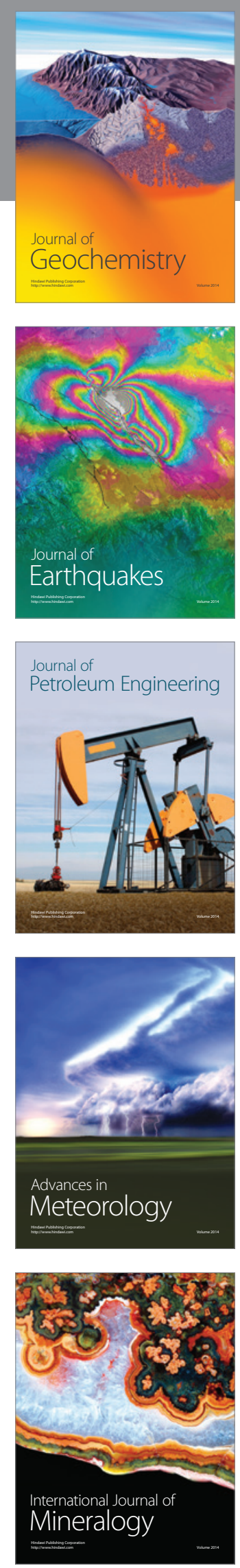
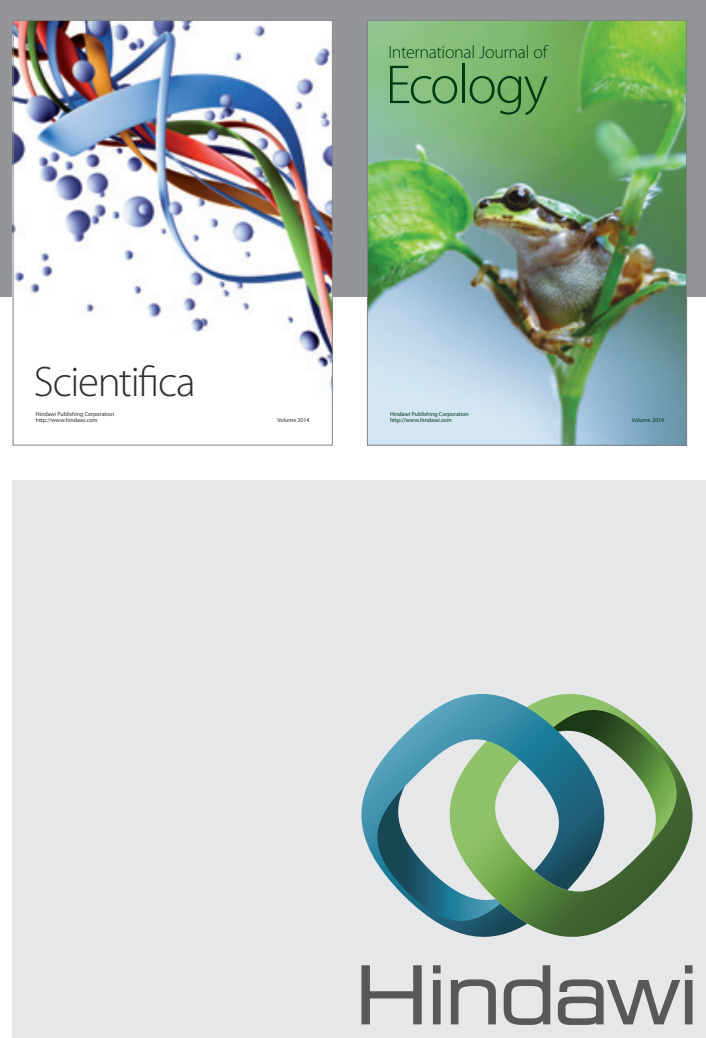

Submit your manuscripts at

http://www.hindawi.com
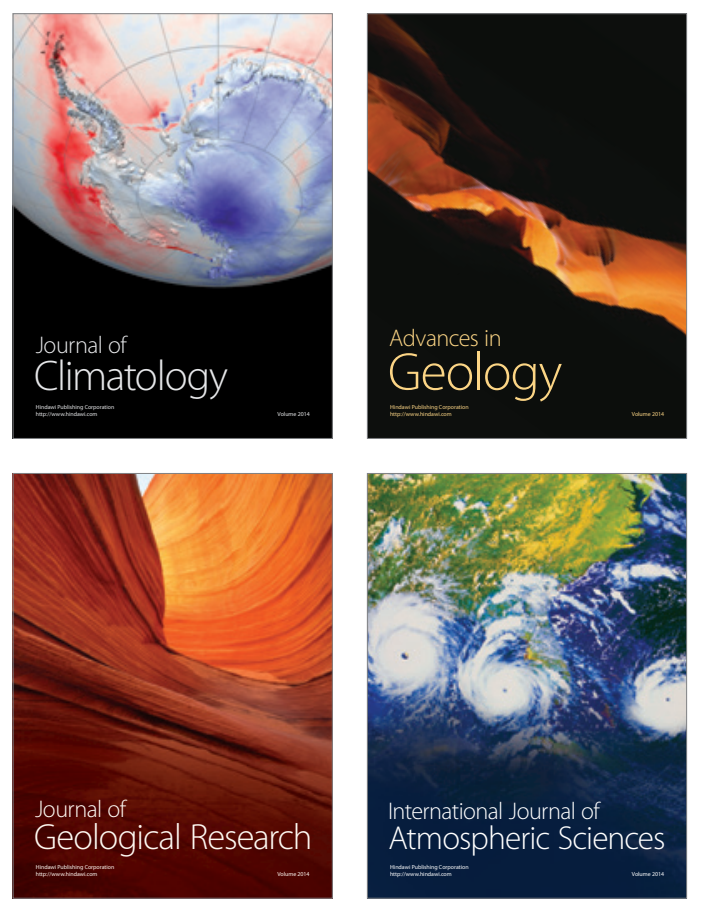

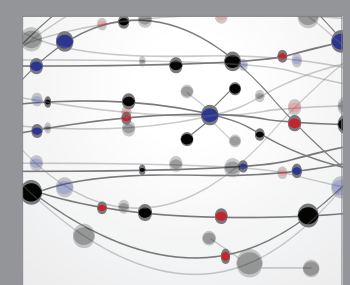

The Scientific

\section{World Journal}
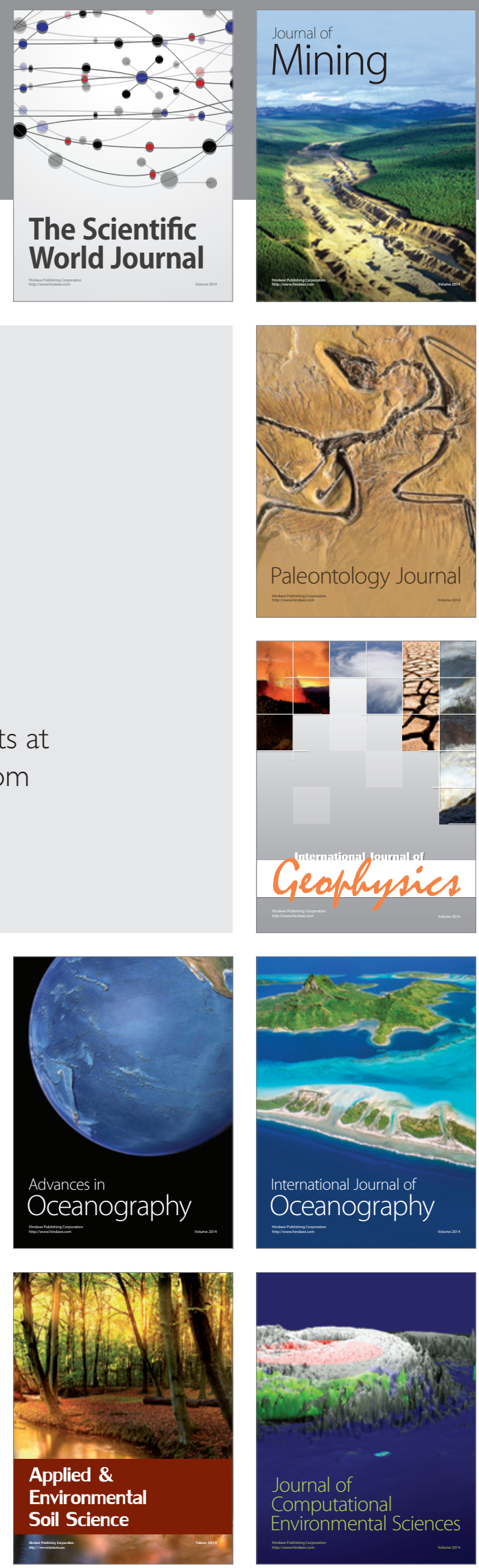